This item was submitted to Loughborough's Institutional Repository (https://dspace.lboro.ac.uk/) by the author and is made available under the following Creative Commons Licence conditions.

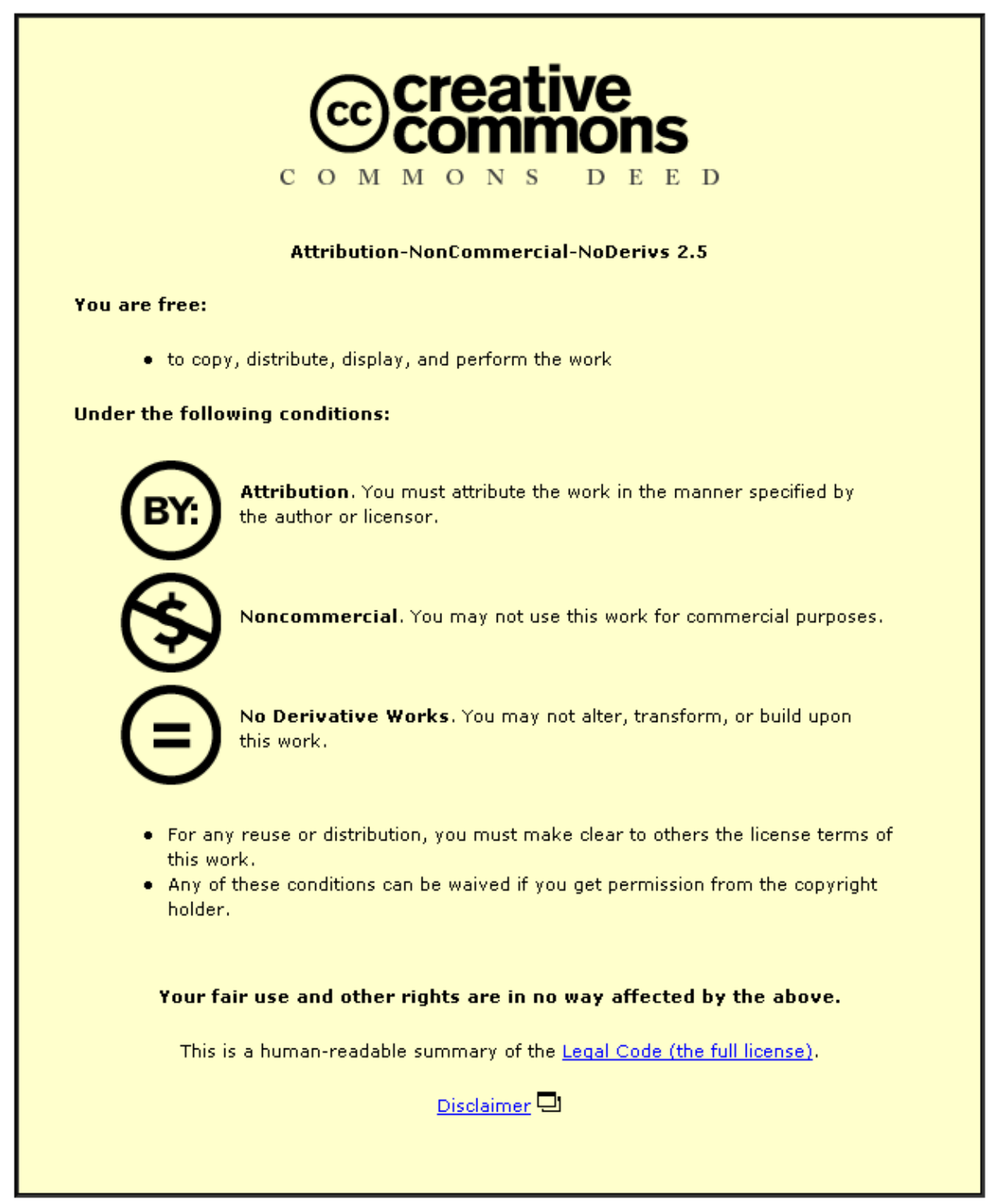

For the full text of this licence, please go to: http://creativecommons.org/licenses/by-nc-nd/2.5/ 


\title{
THE USE OF ELECTRODE PROBES IN DETERMINATIONS OF FILTER CAKE FORMATION AND BATCH FILTER SCALE-UP
}

\author{
E.S. Tarleton (e.s.tarleton@lboro.ac.uk) \\ Department of Chemical Engineering, Loughborough University, Loughborough, Leics., LE11 3TU, \\ UK.
}

\begin{abstract}
A well controlled apparatus was used to obtain new data for constant pressure cake formation in a batch leaf filter which could be fitted with electrode type sensing probes. For aqueous suspensions of calcite and talc, the influence of the intrusive electrodes on cake formation was quantified with respect to filtration parameters. As the electrode length and diameter were altered such that the projected cross-sectional area occupied up to $2.6 \%$ of the filter area, the average specific cake resistance (as determined by classical filtration theory) was observed to increase by up to $49 \%$ and the average cake porosity decreased by up to $21 \%$. When the electrodes were small relative to the dimensions of the filter cell, their influence on macroscopic cake properties was low. The additional information which electrical resistance measurements provide is discussed in relation to the results and observations by previous researchers and the benefits to filter test analysis and batch filter calculations are highlighted. For moderately compressible cake filtrations it is postulated that the incorrect assessment of cake porosity can typically account for an $\sim 12 \%$ error in scale-up calculations for batch filters.
\end{abstract}

\section{KEYWORDS}

Cake filtration; Compressibility; Tomography; Scale-up; Electrode probes; Batch filter

\section{INTRODUCTION}

The need to better understand the formation and post-treatment of compressible filter cakes has provided much of the impetus for filtration research and the topics have underpinned a considerable literature. Although the latter may appear disjointed to the non-expert, it is clear that a number of works (e.g. Tiller (1953); Shirato et al. (1985); Wakeman et al. (1991); Tarleton and Willmer (1997)) have established that filter cake structure alters with time and spatial position according to the process conditions and the degree of compressibility in the forming cake. Our current level of knowledge necessitates that the concepts of cake compressibility and structure are quantified according to 'constitutive equations', examples of which relate average specific cake resistance, $\alpha_{a v}$, and porosity, $\varepsilon_{a v}$ (for instance), to filtration pressure through empirically derived constants. Forms of the constitutive equations are used in some of the relatively few recognised scale-up procedures for filtration and these provide the basis for practical process models and simulations (Wakeman and Tarleton (1999)). Inaccuracies in their determination will inevitably lead to incorrect filter sizing and poorer predictions of filter performance.

To establish characterising parameters for filtration it is common practice to perform sequences of constant pressure and/or vacuum experiments and analyse the resultant data with the aid of cake samples. The difficulties of taking representative cake samples and the desire to assess in-situ cake formations has lead researchers to the development, though not widespread adoption, of alternative techniques which in some cases facilitate the near continuous determination of cake structure throughout an experiment. Methods relevant to filtration include the use of intrusive electrodes (Rietema (1953); Baird and Perry (1968); Dobson (1970); Wakeman (1981); Holdich (1990); Tarleton and Hancock (1996 and 1997)) or pressure probes (Shirato et al. (1980); Willis et al. (1983); Murase et al. (1989); Wu (1994); Fathi-Najafi and Theliander (1995)), flush mounted 
electrodes (Shirato et al. (1971); Shirato and Aragaki (1972)) or pressure probes (Harvey et al. (1988)) and X-rays or high energy radiation (Bierck et al. (1988); Bierck and Dick (1990); La Heij et al. (1996); Tiller et al. (1995)). It is noted that similar procedures have also been used to assess related processes such as sedimentation, filter cake deliquoring and microfiltration (Wakeman and Holdich (1984); Wakeman and Vince (1986); Holdich and Sinclair (1992); Shi et al. (1993)). Although the measurement techniques employed in filtration differ in detail, the generic arrangements are similar and the advantages and disadvantages can be summarised as shown in Table 1. It is evident that all methods have some inherent deficiencies and there are compromises between factors such as (potential) accuracy, speed of measurement, ease of use and cost. This paper presents some experiments and relates their data to the wider issues of using intrusive sensing probes in filtration and filter scale-up calculations.

\section{EXPERIMENTAL PROCEDURES AND RESULTS}

The principal components of the experimental test apparatus are shown in Figure 1 and some properties of the test suspensions are given in Table 2. Briefly, the apparatus comprised a leaf filter of internal diameter $102 \mathrm{~mm}$ (filtration area $\sim 82 \mathrm{~cm}^{2}$ ), an electronic balance, a personal computer and an electrode sensing system, all connected by suitable piping and wiring interfaces. In each test a downward filtration was performed using compressed air at a constant pressure between $0 \& 600 \mathrm{kPa}$. A homogenous aqueous suspension of either calcite or talc ${ }^{\dagger}$ at $^{\mathrm{known} \mathrm{pH}}$ was fed into the filter cell where solids accumulated on the filter medium as cake and filtrate passed into a container on the computer interfaced balance to be automatically weighed at set time intervals. In some cases the computer was also interfaced via a control box to a set (or sets) of removable and diametrically opposed electrode pairs positioned in vertical planes within the filter cell. When the probes were connected the computer controlled the switching of the electrode pairs to allow reversing polarity resistance measurements. These were recorded and then converted through calibrations to give real time measures of transient cake thickness and porosity distribution (see also Tarleton and Hancock (1997) \& Holdich and Sinclair (1992) for more details). Wherever possible experiments were repeated to ensure reproducibility.

Figure 2 shows examples of typical filtration data for $10 \% \mathrm{v} / \mathrm{v}$ suspensions and no electrode probes. These serve to illustrate the operation and general reproducibility of the experimental apparatus when forming representative low and moderately compressible cakes. For the three nearly incompressible calcite filtrations $\alpha_{a v}$ (as determined by classical filtration theory) was calculated as $1.1 \times 10^{10} \mathrm{~m} \mathrm{~kg}^{-1}$ and $\varepsilon_{a v}$ measured as 0.61 whilst for the three moderately compressible talc filtrations the corresponding values were $8 \times 10^{10} \mathrm{~m} \mathrm{~kg}^{-1}$ and 0.70 .

Some researchers have suggested, though seemingly failed to quantify, how determinations of cake structure by intrusive electrode probes are erroneous due to the physical influence of the probes on cake formation (Shirato et al. (1971 and 1985)). In an attempt to assess this, a series of experiments were performed using a filtration pressure of $100 \mathrm{kPa}$, a feed concentration of $10 \% \mathrm{v} / \mathrm{v}$ and electrodes of different length $(0-50 \mathrm{~mm})$ and diameter $(0-3.5 \mathrm{~mm})$. Figure 3 shows the arrangement of the diametrically opposed electrodes positioned at regular $10 \mathrm{~mm}$ vertical intervals within the filter cell. To determine the effects of length the electrode diameter was fixed at $1.5 \mathrm{~mm}$ and for the assessment of electrode diameter the length was arbitrarily fixed at $30 \mathrm{~mm}$. For these tests the electrodes were not connected to the computer, average cake porosities were determined by consistent and careful mass sampling and calculations of average specific cake resistance were made using classical filtration theory. Figures 4 and 5 illustrate the effects of electrode length on the characteristic measures of filtration. For the suspensions tested, average specific cake resistance tended to marginally increase as the electrode length was raised, and the increase appeared to be more pronounced with the more compressible talc filtrations. With longer

\footnotetext{
${ }^{\dagger}$ Representative data for a zinc sulphide filtration are also shown in the paper to illustrate the potential accuracy of measurements by electrical resistance.
} 
electrodes the measured cake porosity tended to decrease and was particularly reduced for one of the calcite experiments when the electrodes were of sufficient length to effectively traverse the diameter of the filter cell. Figures 6 and 7 show how electrode diameter had relatively little influence on cake formation for the nearly incompressible calcite filtrations. With the more compressible talc system, however, there was a significant increase in specific cake resistance at larger electrode diameters which accompanied a gradual, although less progressive reduction in the measured cake porosity.

As an illustration, Figures 8 and 9 show typical examples of transient solids concentration measurements from computer activated electrodes; in these cases electrode length and diameter were restricted to the more normal $3 \mathrm{~mm}$ and $1 \mathrm{~mm}$ respectively. For the near incompressible system shown in Figure 8 cake formed at an almost uniform solids concentration of $\sim 39 \% \mathrm{v} / \mathrm{v}$. Although the thickness increased with time, there was little transient change in the measured solids concentrations despite the progressive growth of cake upon the layers formed closest to the filter medium. Figure 9 shows corresponding data for more compressible talc filtrations at two distinct constant pressures. Here, cake formed with a much greater range of solids concentrations which generally increased as time progressed due to particle rearrangements at the microscopic scale. By (careful) mass sampling of cakes it was also possible to compare physical measurements of cake solids concentration with readings taken using the electrodes. Figure 10 shows a typical example of the experimental data obtained and this is in accordance with previous theoretical work which attempted to quantify the accuracy of similar measurements (Chase et al. (1990)).

\section{DISCUSSION}

Although intrusive electrodes (and pressure probes) have been used on occasion in previous laboratory scale filtration research, the experimental data in Figures 4-7 provide rare quantitative measures of their effects on cake formation in a batch leaf filter. Whilst the particles and fluid moving past electrodes will experience disturbed microscopic flow patterns, it seems that macroscopic cake formation and properties are only significantly altered over more extreme ranges of electrode length and diameter. The comparative data obtained suggest that when electrodes are relatively short (say $3 \mathrm{~mm}$ ) and of a small diameter (say $1 \mathrm{~mm}$ ) cake formation proceeds (for practical purposes) essentially unhindered to give similar cake properties to those obtained with no electrodes. This would be intuitively as expected provided both the particulates filtered and the physical dimensions of the electrodes are small in relation to the physical dimensions of the filter cell and the filtration rate is sufficiently low to prevent significant alterations of particulate properties by the mechanical interference of the electrodes.

It is perhaps surprising that intrusive electrodes (which are at least $10 \mathrm{~mm}$ above the filter medium and vertically separated by $10 \mathrm{~mm}$ ) should influence cake formation at all significantly. For the filter cell tested, an electrode pair having a diameter of $1.5 \mathrm{~mm}$ and a combined length of $100 \mathrm{~mm}$ projected a cross-sectional area equivalent to $\sim 1.9 \%$ of the available filter area. In the calcite and talc experiments, such an electrode arrangement raised the measured average cake resistances by $23 \%$ and $8 \%$ respectively whilst average cake porosities were reduced by $21 \%$ and $5 \%$ respectively from the values recorded with no electrodes. An electrode pair with a combined length of $60 \mathrm{~mm}$ and a diameter of $3.5 \mathrm{~mm}$ projected over $\sim 2.6 \%$ of the available filter area and such an arrangement raised the cake resistances by $17 \%$ and $49 \%$ and lowered the cake porosities by $0 \%$ and $4 \%$ for calcite and talc filtrations respectively. Alterations to filter performance are apparently considerable in some instances and assuming the data to be representative, it is clear that the use of anything but relatively small electrodes is to be avoided. What is less clear is correlating the occasionally significant change in measured porosity with the calculated change in specific cake resistance, although the trend of a reduced porosity coupled with an increased resistance was generally observed. When attempting to interpret such information the relative dimensions of the particles in the feed to the electrode and filter cell 
dimensions must be noted. In most of the filtration experiments there were at least several thousand mean particle diameters of horizontal separation between the electrodes of a diametrically opposed pair. This would suggest that the degree of 'flexibility' in the cake structure should be sufficient to accommodate relatively minor interference at the cake periphery without gross changes in macroscopic cake properties. With the current level of knowledge and investigation it is unfortunately only possible to postulate the reasons for the sometimes substantial effects observed.

Of the previous work known to the author, that concerned with the effects of intrusive probes on cake formation is presented almost exclusively in a qualitative manner. Shirato et al. (1971 and 1985) and Murase et al. (1989), for instance, have suggested that intrusive horizontal electrodes will tend to mechanically interfere with cake formation. The inference being that such probes artificially support a growing filter cake leading to a decrease in the effective resistance. Other work (Rietema (1953); Baird and Perry (1968); Fathi-Najafi and Theliander (1995); Sörensen et al. (1995); Chase et al. (1994); Tarleton and Willmer (1997)), some of which uses intrusive probes of various types, has reported the so-called 'retarded packing compressibility (or RPC)' where a forming cake structure undergoes a seemingly rapid collapse to a new pseudo-equilibrium state. A proposed mechanism is that a cake structure is artificially supported by intrusive probes and initially stabilised by higher interstitial liquid flows to an extent that when the filtration rate falls below a critical level (or perhaps a critical cake thickness is reached) at least part of the cake structure becomes unstable. The data presented in this paper does not appear to corroborate the theory that intrusive probes support a filter cake to any significant extent or indeed notably affect cake formation provided they are of sufficiently small dimensions. Such findings do not, however, indicate that RPC is anything but a real phenomenon as it has been observed in filtration by several authors both with and without the inclusion of intrusive probes. The evidence suggests, however, that RPC can potentially occur whenever a forming cake exhibits a degree of flow (or otherwise) induced structure and it commences upon the establishment of a set of as yet unidentified, but critical, conditions which lead to collapse. If it is correct that intrusive probes do not lead to significant changes in cake properties and/or the onset of RPC then the benefits to be gained from their use in the laboratory, and perhaps at larger scales, are significant. By using small intrusive electrodes, rather than (for instance) the larger flush mounted variant or pressure transducers, the number of probes available to give measurements during filtration is substantially increased. Moreover, such electrode probes can offer significant advantages over many of the other techniques shown in Table 1 whereby measurements are taken relatively quickly and there is the potential for determinations of liquor and solute transport rates during all phases of a filter cycle including cake deliquoring and washing (Tarleton and Hancock (1997)).

The illustrative data shown in Figures 8 and 9 highlight some of the measurements which electrode probes facilitate during cake formation. Such determinations are important in both batch filter testing and the establishment of correct process models for filter sizing and simulation (Wakeman and Tarleton (1999); Purchas and Wakeman (1986)). Whilst there are few (if any) apparatus standards or procedures in pressure filter testing, most (constant pressure) filtration experiments are performed in the laboratory using versions of a single leaf or pressure vessel filter. The filter surface is either upward facing and positioned toward the bottom of a pressure vessel (e.g. in a form similar to Figure 1) or vertically oriented and held separately within a unit contained inside a pressure vessel containing slurry (the so-called 'bomb' filter). Experiments with such units can be difficult to perform reliably unless automation is used or great care and strict procedures are followed and this translates to the recommended use of at least a $25 \%$ factor of safety on subsequent scale-up calculations (see also Tarleton and Willmer (1997)). A generalised factor of safety will cover potential errors from a number of sources, one of which, the measurement of cake concentration or porosity, is integral to process simulation calculations.

For a compressible cake of given properties the structure will change with time as filtration proceeds in relation to factors such as the magnitude of the applied pressure and the growth rate of cake. These factors combine to present a cake which generally exhibits a porosity distribution 
throughout its height and the need to establish correct values for porosity in a batch filter becomes readily apparent when consideration is given to determinations of filter area $(A)$ in process simulation where a solids mass balance gives:

$$
A=\frac{M_{s}\left(\rho_{s}\left(m_{a v}-1\right)+\rho_{l}\right)}{\rho_{s} \rho_{l} L}
$$

and

$$
m_{a v}=1+\frac{\rho_{l}}{\rho_{s}}\left(\frac{\varepsilon_{a v}}{1-\varepsilon_{a v}}\right)
$$

where $M_{s}$ is the required mass of solids in the cake, $\rho_{l}$ and $\rho_{s}$ the liquid and solids densities respectively, $m_{a v}$ the (average) ratio of mass wet/dry cake and $L$ is the cake thickness. Assuming a constant filtration pressure, equation (1) implies that for a given suspension, $M_{s}$ (which is fixed by process requirements) and $L$ (frequently fixed by the physical constraints of filter construction), the predicted filter area is determined by the value of $m_{a v}$. If $m_{a v}$ is lower, such as that determined towards the end of a longer filtration or evaluated from a sample of cake taken only from a position close to the filter medium, then the calculated filter area will be smaller. Conversely when $m_{a v}$ is larger, such as that generally exhibited towards the start of a filtration, then a larger filter area is calculated and there is an inherently larger factor of safety in the scale-up procedure. Whilst it is recommend (Purchas and Wakeman (1986)), though not always practised, procedure for the whole cake to be weighed at the end of a batch filter test such a methodology is not always easy to perform in reality and is potentially prone to significant errors. Furthermore, although a recommended maximum height of $25 \mathrm{~mm}$ has been suggested for some laboratory scale pressure filter tests (Purchas and Wakeman (1986)), there is little recommendation for a time period over which to perform a test and thus significant scope exists for errors in the determination of characteristic filtration parameters from either a single test or a sequence of tests at different constant pressures. Using the data in Figure 9 as an example ${ }^{\dagger}$ and assuming a maximum cake thickness of $25 \mathrm{~mm}$, then depending on the solids concentration considered to be cake, the filtration time and cake sample taken it is feasible for even an experienced experimentalist to inadvertently determine a value of $m_{a v}$ in the range $\sim 1.80-1.58(\sim 12 \%$ difference $)$ and instigate an erroneous filter scale-up. Although it is hoped that a filter sizing would not be based on just one test, the potential for introducing significant errors in filtration tests and thus subsequent calculations is ever present and to a degree which is not always predictable a priori. From data such as Figure 9, it should be clear that the use of more sophisticated experimental apparatus incorporating the facility for transient measurements of $m_{a v}$ (and hence calculations of $\alpha_{a v}^{\ddagger}$ ) allows for improved scale-up and process calculations as well as an ability to assess the range of sensitivity over which these parameters influence filter performance.

\section{CONCLUSIONS}

The work described in this paper represents part of a co-ordinated research program which aims to establish and integrate robust experimental and analysis procedures to facilitate the process modelling and simulation of the range of batch and continuous filters used in industrial applications. Whilst these ultimate objectives can only be realised at some time in the future, the work presented in this paper (as well as some of the authors other recent work (e.g. Tarleton and

\footnotetext{
${ }^{\dagger}$ Other data obtained by the author for talc and china clay filtrations have confirmed the findings presented.

${ }^{\ddagger}$ It is noted in passing that errors in $m_{a v}$ tend to become more significant for higher concentration feeds as the effect on calculations of $\alpha_{a v}$ is increased.
} 
Hancock (1996 and 1997); Tarleton and Willmer (1997); Tarleton (1998))) provides for some progression. The illustrative data presented highlight some of the benefits of routinely monitoring transient cake formation and quantify both the influence of intrusive electrodes on cake formation and the potential scale-up errors which can be introduced by the inappropriate use of filtration test data.

Several researchers have previously indicated a need to monitor variations in cake porosity due to its importance in filtration modelling (e.g. Tiller (1953); Shirato et al. (1985); Wakeman (1981); Stamatakis and Tien (1991); Theliander and Fathi-Najafi (1995)). Whilst many of the models have yet to find a widespread use outside of academia, some can be incorporated into process simulations (Wakeman and Tarleton (1990, 1994 and 1999); Tarleton and Wakeman (1994)). Although further work is probably needed to establish robust scale-up procedures and prove these simulations at the larger scale, their potential is clear and they can only help to bring filtration simulations up to the standard available for predictions of other unit operations.

\title{
NOMENCLATURE
}

\author{
A filter area $\left(\mathrm{m}^{2}\right)$ \\ $L \quad$ cake thickness $(m)$ \\ $m_{a v} \quad$ average ratio of the mass or wet/dry cake (-) \\ Greek symbols \\ $\alpha_{a v} \quad$ average specific cake resistance $\left(\mathrm{m} \mathrm{kg}^{-1}\right)$ \\ $\varepsilon_{a v} \quad$ average cake porosity (-) \\ $\rho_{l} \quad$ liquid density $\left(\mathrm{kg} \mathrm{m}^{-3}\right)$ \\ $\rho_{s} \quad$ solids density $\left(\mathrm{kg} \mathrm{m}^{-3}\right)$
}

\section{REFERENCES}

Baird R.L. and Perry M.G., The distribution of porosity in filter cakes, Filtration and Separation, 1968, 5, 471.

Bierck B.R. and Dick R.I., In-situ examination of effects of pressure differential on compressible cake filtration, Water Science and Technology, 1990, 22(12), 125.

Bierck B.R., Wells S.A. and Dick R.I., Compressible cake filtration: monitoring cake formation and shrinkage using synchrotron X-rays, J. Water Pollution Control, 1988, 60(5), 645.

Chase G.G., Steffen J. and Ott D., Microscopic observation of filter cake formation, Separation Technology, 1994, 4, 118.

Chase G.G., Willis M.S. and Kannel J., Averaging volume size determinations of electroconductive porosity probes, International J. Multiphase Flow, 1990, 16(1), 103.

Dobson B., Continuous rotary vacuum filtration, $P h D$ thesis, 1970, University of Sheffield.

Fathi-Najafi M. and Theliander H., Determination of local filtration properties at constant pressure, Separation Technology, 1995, 5, 165.

Harvey M.A., Bridger K. and Tiller F.M., Apparatus for studying incompressible and moderately compressible cake filtration, Filtration and Separation, 1988, 23(1), 21.

Holdich R.G., Solids concentration and pressure profiles during compressible cake filtration, Chemical Engineering Communications, 1990, 91, 255. 
Holdich R.G. and Sinclair I., Measurement of slurry solids content by electrical conductivity, Powder Technology, 1992, 72, 77.

La Heij E.J., Kerkhof P.J.A.M., Kopinga K. and Pel L., Determining porosity profiles during filtration and expression of sewage sludge by NMR imaging, American Institute Chemical Engineers J., 1996, 42(4), 953.

Murase T., Iritani E., Cho J.H. and Shirato M., Determination of filtration characteristics based upon filtration tests under step-up pressure conditions, J. Chemical Engineering of Japan, 1989, 22(4), 373.

Purchas D.B. and Wakeman R.J. (Eds.), Solid/liquid Separation Equipment Scale-up, $2^{\text {nd }}$ Edn., 1986, Uplands Press, London.

Rietema K., Stabilising effects in compressible filter cakes, Chemical Engineering Science, 1953, 2, 88.

Shi T.M., Simons S.J.R., Dickin F.J. and Williams R.A., Electrical sensing of dispersion behaviour, Colloids and Surfaces, 1993, 77, 9.

Shirato M., Aragaki T., Ichimura K. and Ootsuti N., Porosity variation in filter cakes under constant pressure filtration, J. Chemical Engineering of Japan, 1971, 4, 172.

Shirato M., and Aragaki T., Verification of internal flow mechanism theory of cake filtration, Filtration and Separation, 1972, 9(3), 290.

Shirato M., Aragaki T., Iritani E. and Funahashi T., Constant rate and variable pressure-variable rate filtration of power-law non-Newtonian fluids, J. Chemical Engineering of Japan, 1980, 13(6), 473.

Shirato M., Sambuichi A., Murase T., Aragaki T., Kobayashi K. and Iritani E., Theoretical and experimental studies in cake filtration, Memoirs of the Faculty of Engineering (Nagoya University), 1985, 37(1), 38.

Sörensen P.B., Christensen J.R. and Bruus J.H., Effect of small scale solids migration in filter cakes during filtration of waste water solids suspensions, Water Environmental Research, 1995, 67(1), 25.

Stamatakis K. and Tien C., Cake formation and growth in cake filtration, Chemical Engineering Science, 1991, 46(8), 1917.

Tarleton E.S., A new approach to variable pressure filtration, Minerals Engineering, 1998, 11(1), 53.

Tarleton E.S. and Hancock D.L., The imaging of filter cakes through electrical impedance tomography, Filtration and Separation, 1996, 33(6), 491.

Tarleton E.S. and Hancock D.L., Using mechatronics for the interpretation and modelling of the pressure filter cycle, Transactions Institution Chemical Engineers, 1997, 75(A), 298.

Tarleton E.S. and Wakeman R.J., Simulation, modelling and sizing of pressure filters, Filtration and Separation, 1994, 31(4), 393. 
Tarleton E.S. and Willmer S.A., The effects of scale and process parameters in cake filtration, Transactions Institution Chemical Engineers, 1997, 75(A), 497.

Theliander H. and Fathi-Najafi M., Simulation of the build-up of the filter cake, Proc. Filtech Conference, Filtration Society, Karlsruhe, 1995, pp.127-137.

Tiller F.M., The role of porosity in filtration, Chemical Engineering Progress, 1953, 49, 467.

Tiller F.M., Hsyung N.B. and Cong D.Z., The role of porosity in filtration: XII, filtration with sedimentation, American Institute Chemical Engineers J., 1995, 41(5), 1153.

Wakeman R.J., The formation and properties of apparently incompressible filter cakes under vacuum on downward facing surfaces, Transactions Institution Chemical Engineers, 1981, 59, 260.

Wakeman R.J. and Holdich R.G., Theoretical and experimental modelling of solids and liquid pressures in batch sedimentation, Filtration and Separation, 1984, 21(6), 420.

Wakeman R.J., Sabri M.N. and Tarleton E.S., Factors affecting the formation and properties of wet compacts, Powder Technology, 1991, 65, 283.

Wakeman R.J. and Tarleton E.S., Simulation and process design of the filter cycle, Filtration and Separation, 1990, 27(6), 412.

Wakeman R.J. and Tarleton E.S., A framework methodology for the simulation and sizing of diaphragm filter presses, Minerals Engineering, 1994, 7(11), 1411.

Wakeman R.J. and Tarleton E.S., Filtration: Equipment Selection, Modelling and Process Simulation, 1999, Elsevier, Oxford.

Wakeman R.J. and Vince A., Kinetics of gravity drainage from porous media, Transactions Institution Chemical Engineers, 1986, 64, 94.

Willis M.S., Collins R.M. and Bridges W.G., Complete analysis of non-parabolic filtration behaviour, Chemical Engineering Research \& Design, 1983, 61, 96.

Wu Y., An analysis of constant-pressure filtration, Chemical Engineering Science, 1994, 49(1), 831. 


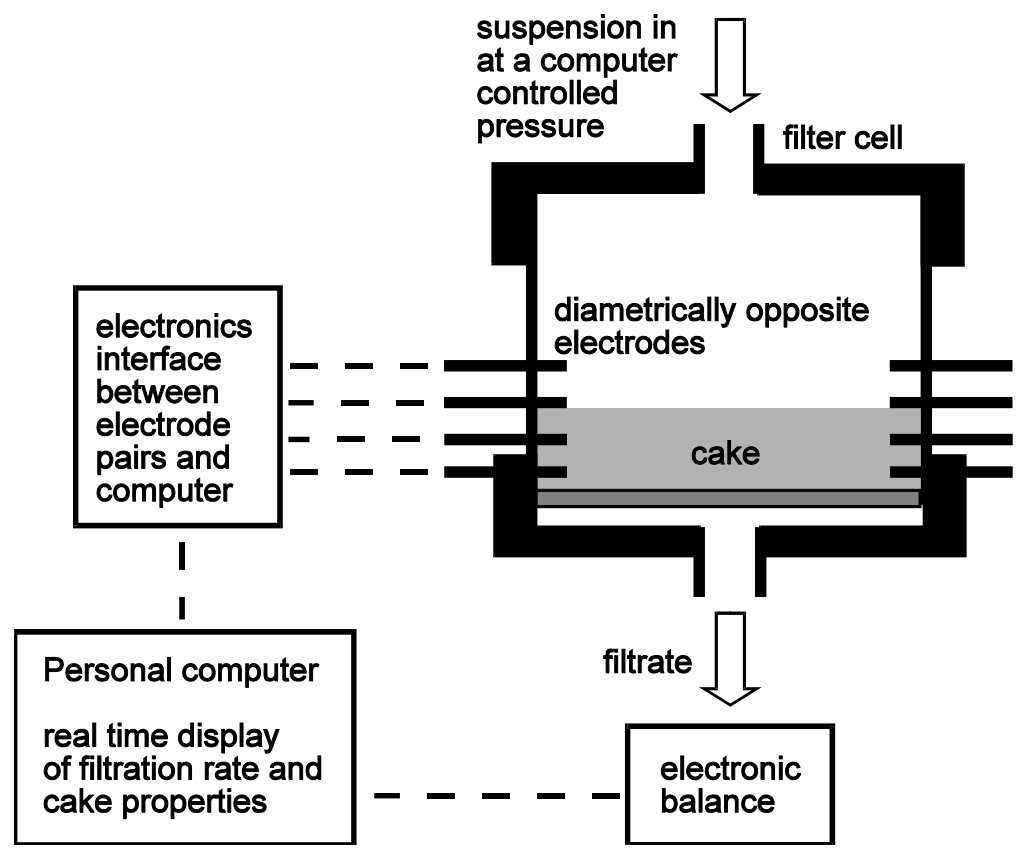

Figure 1: Outline schematic of the experimental filtration apparatus.

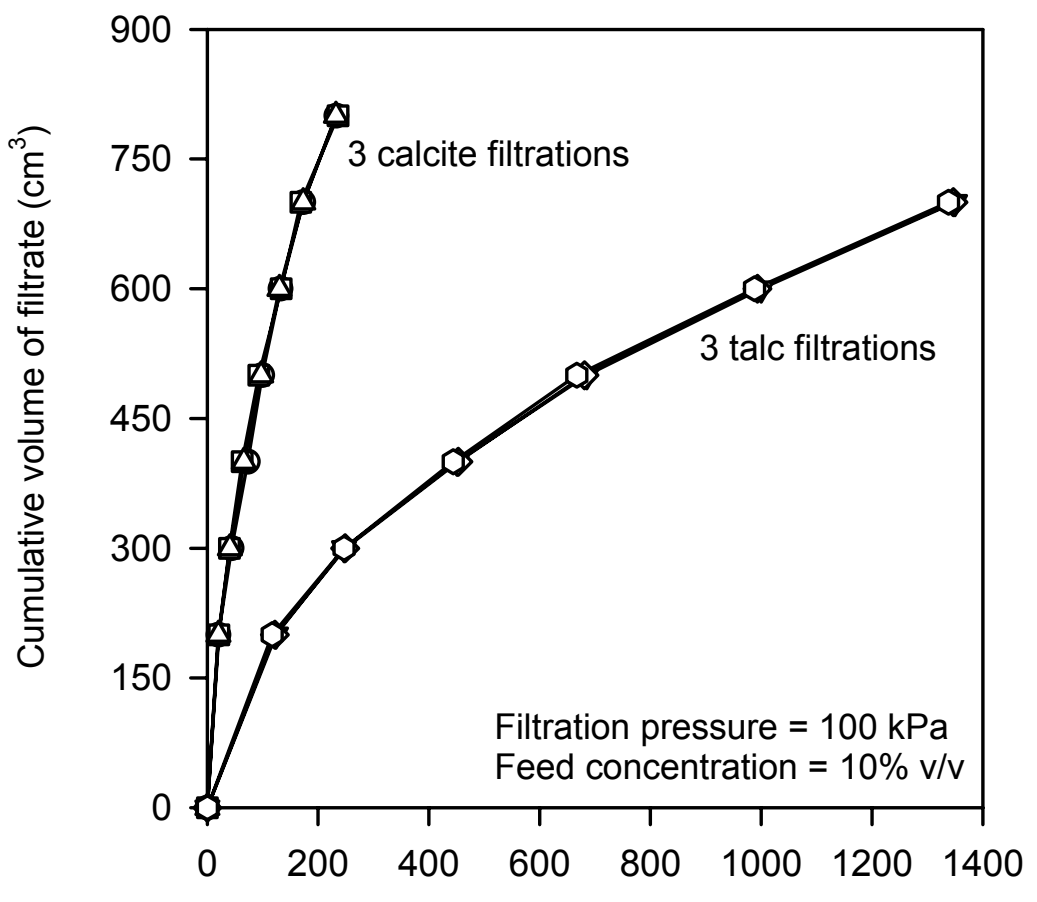

Filtration time (s)

Figure 2: Constant pressure filtration data for $10 \% \mathrm{v} / \mathrm{v}$ calcite and talc suspensions. 


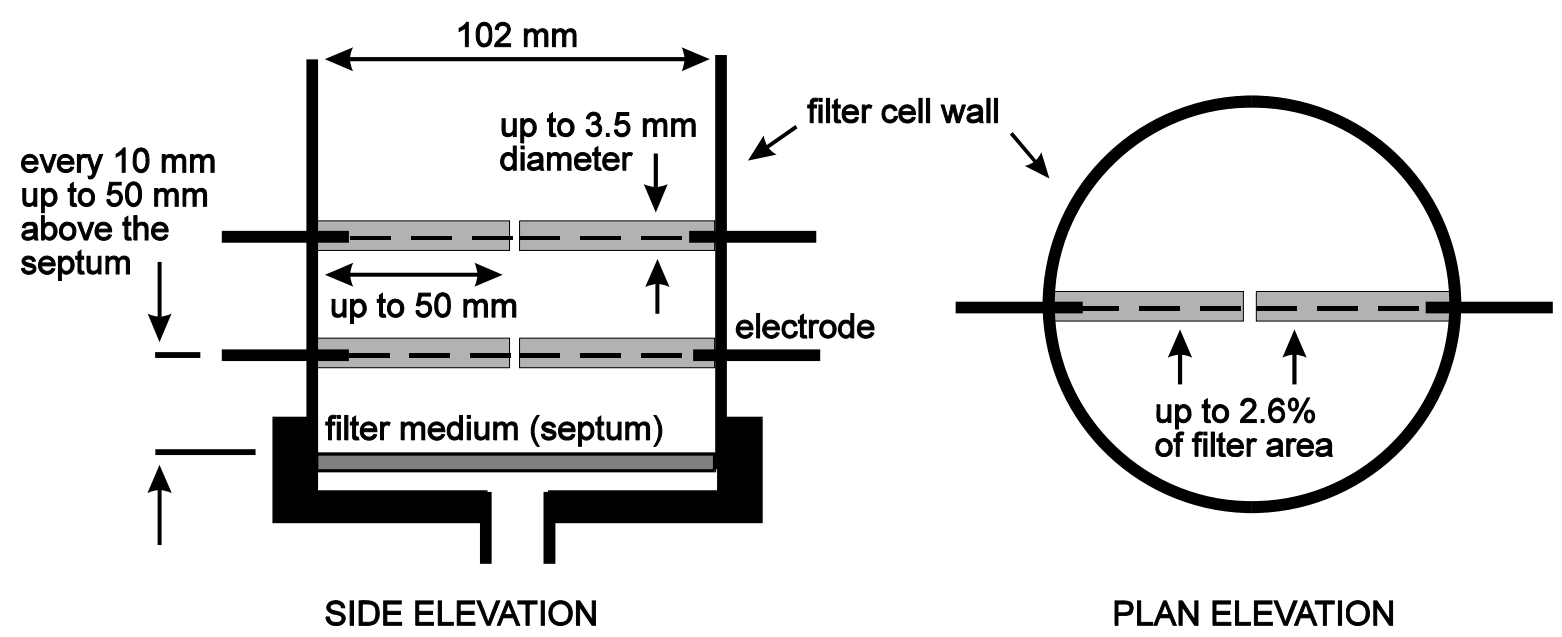

Figure 3: A schematic of the detailed electrode arrangement used to assess the influence of electrode length and diameter on filtration.

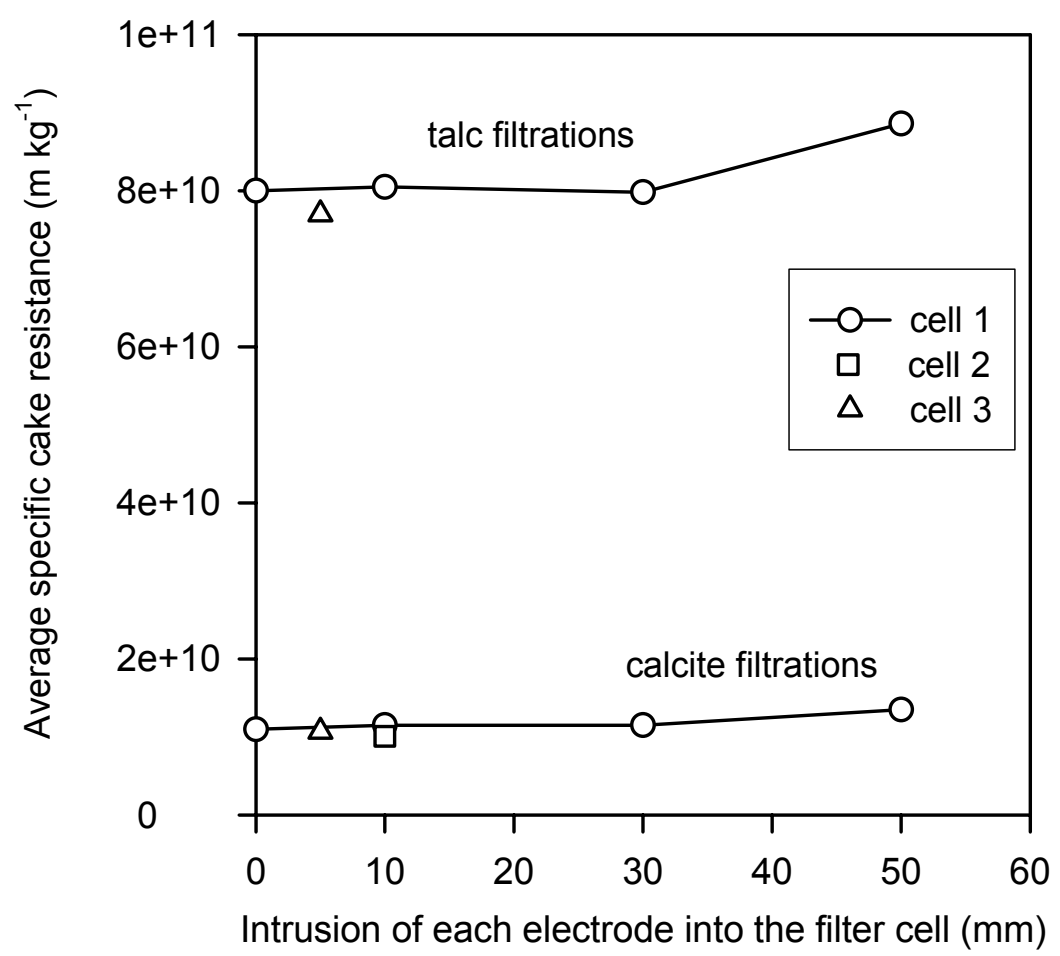

Figure 4: The effects of electrode intrusion on average specific cake resistances for calcite and talc filtrations (Cell 1 is the filter cell described in this paper). For comparison purposes some data from a separate computer controlled experimental apparatus are shown where two other filter cells of area $\sim 80 \mathrm{~cm}^{2}$ were used. Cell 2 had 16 pairs of $\sim 5 \mathrm{~mm}$ long electrodes arranged in a single vertical plane whilst Cell 3 had 256 individual electrodes of $\sim 5 \mathrm{~mm}$ length arranged in several distinct vertical planes. 


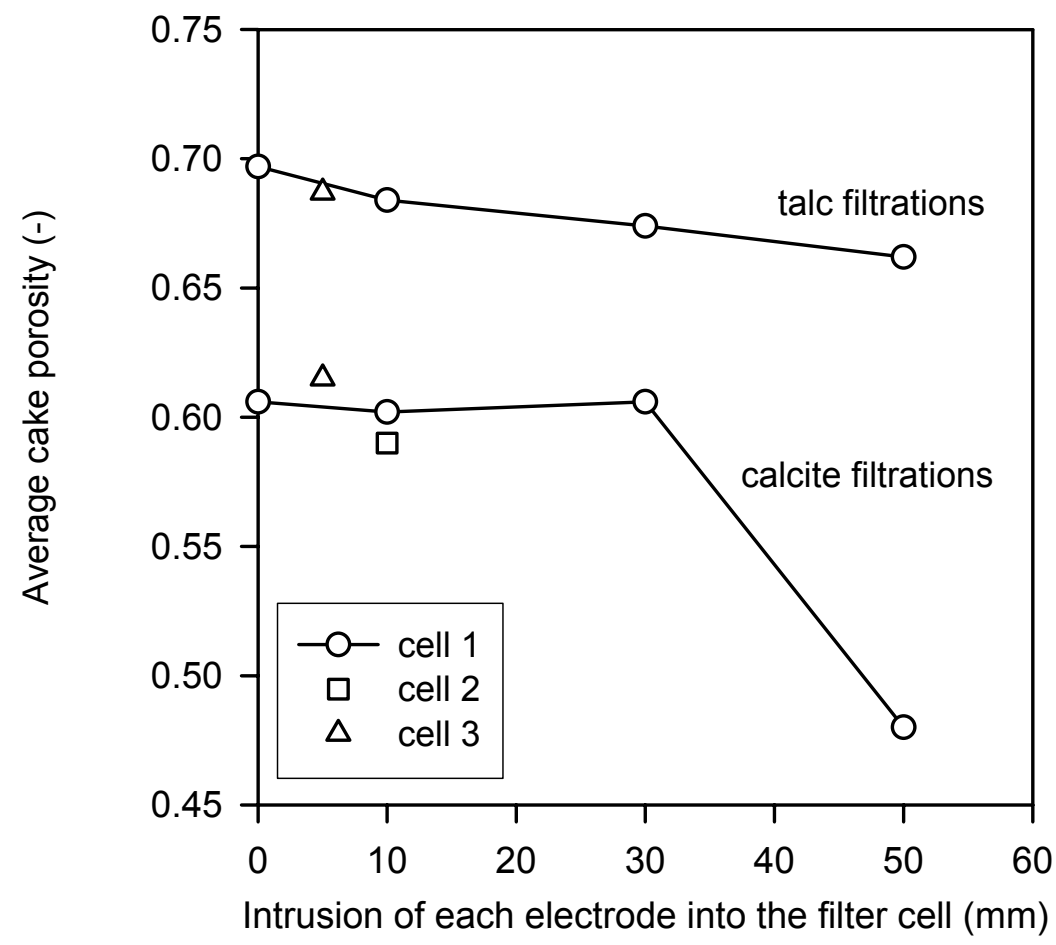

Figure 5: The effects of electrode intrusion on average cake porosities for calcite and talc filtrations (also see the note on Figure 4).

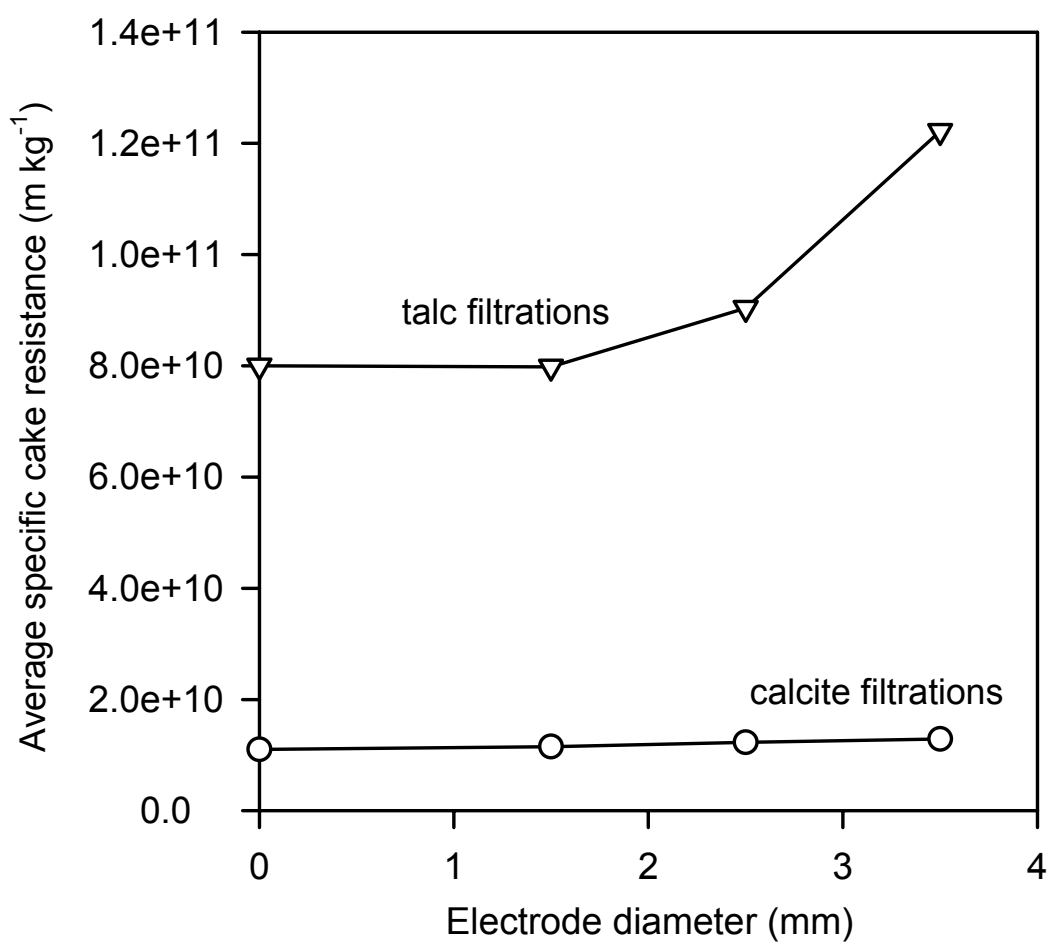

Figure 6: The effects of electrode diameter on average specific cake resistances for calcite and talc filtrations. 


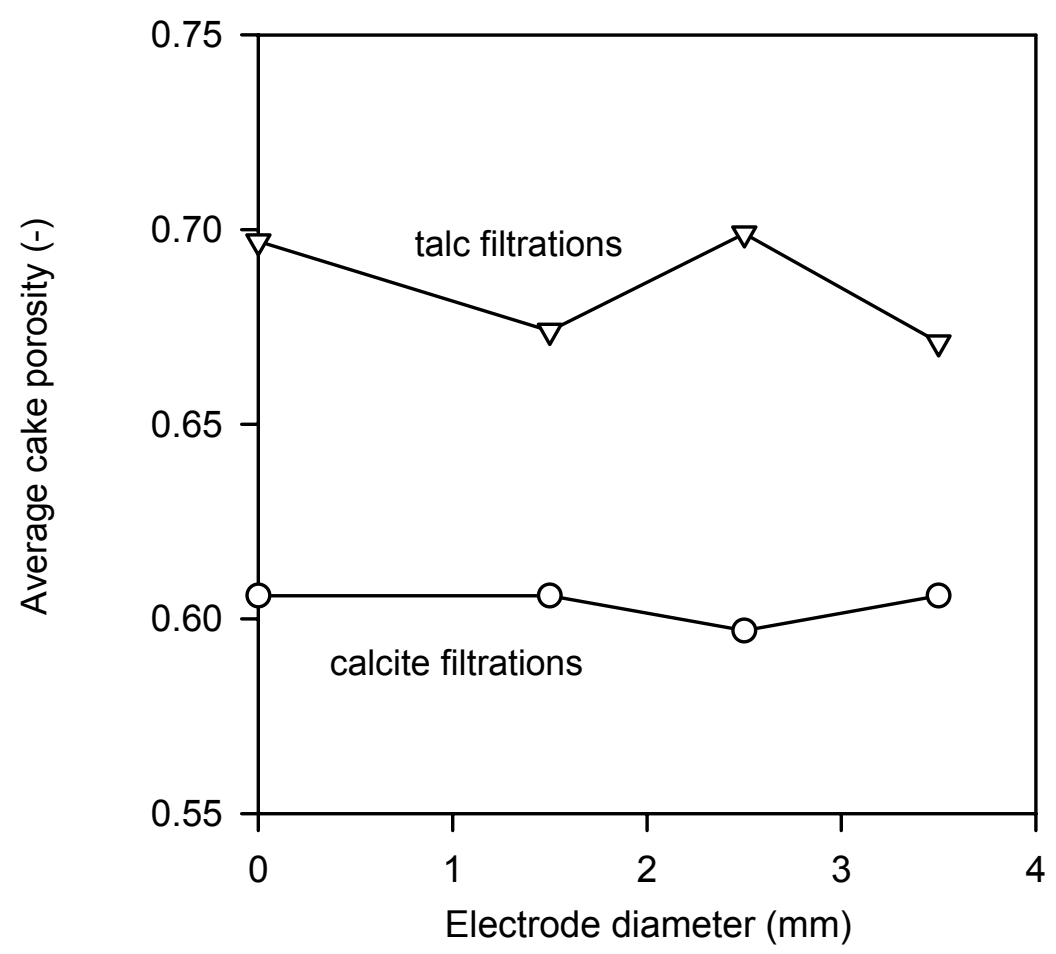

Figure 7: The effects of electrode diameter on average cake porosities for calcite and talc filtrations.

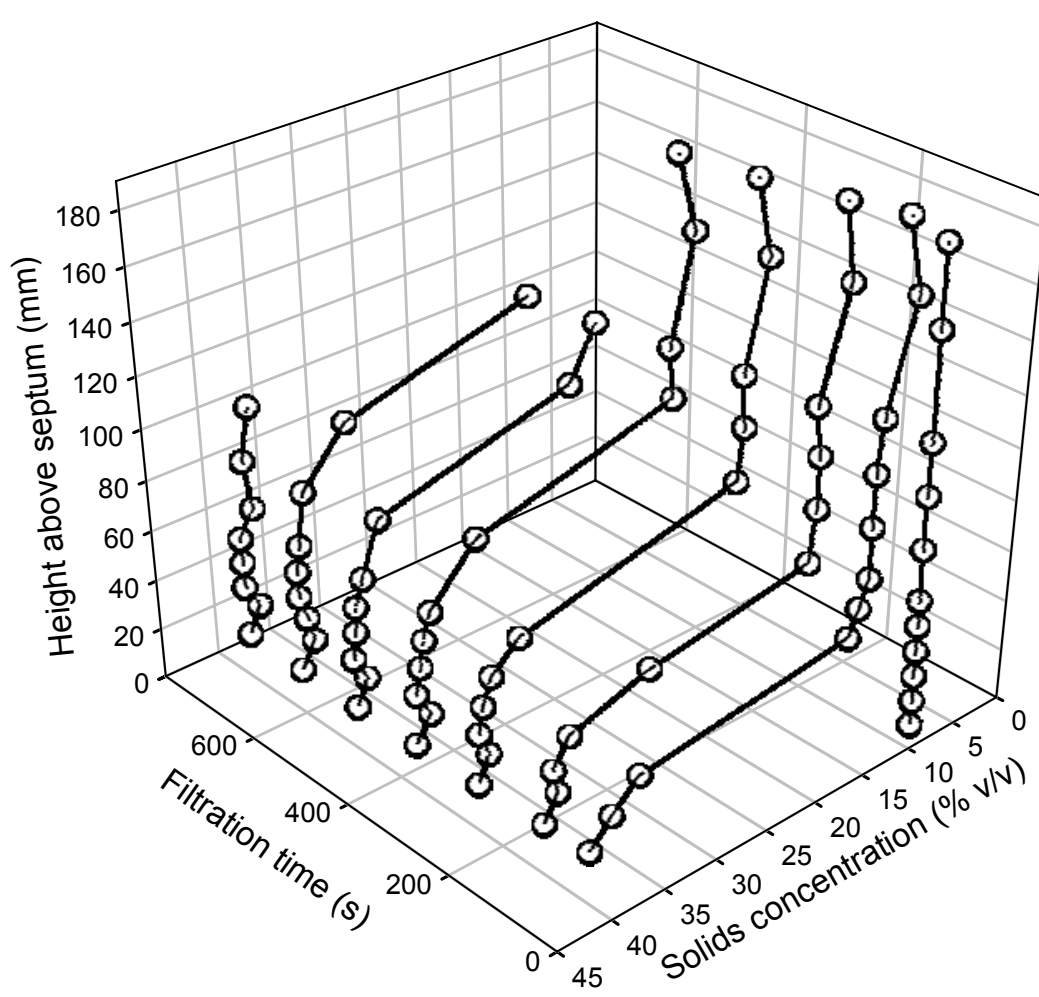

Figure 8: Progressive (near) incompressible cake formation during the constant pressure filtration of a calcite suspension. Filtration pressure $=300 \mathrm{kPa}$; feed concentration $=10 \% \mathrm{v} / \mathrm{v}$. 


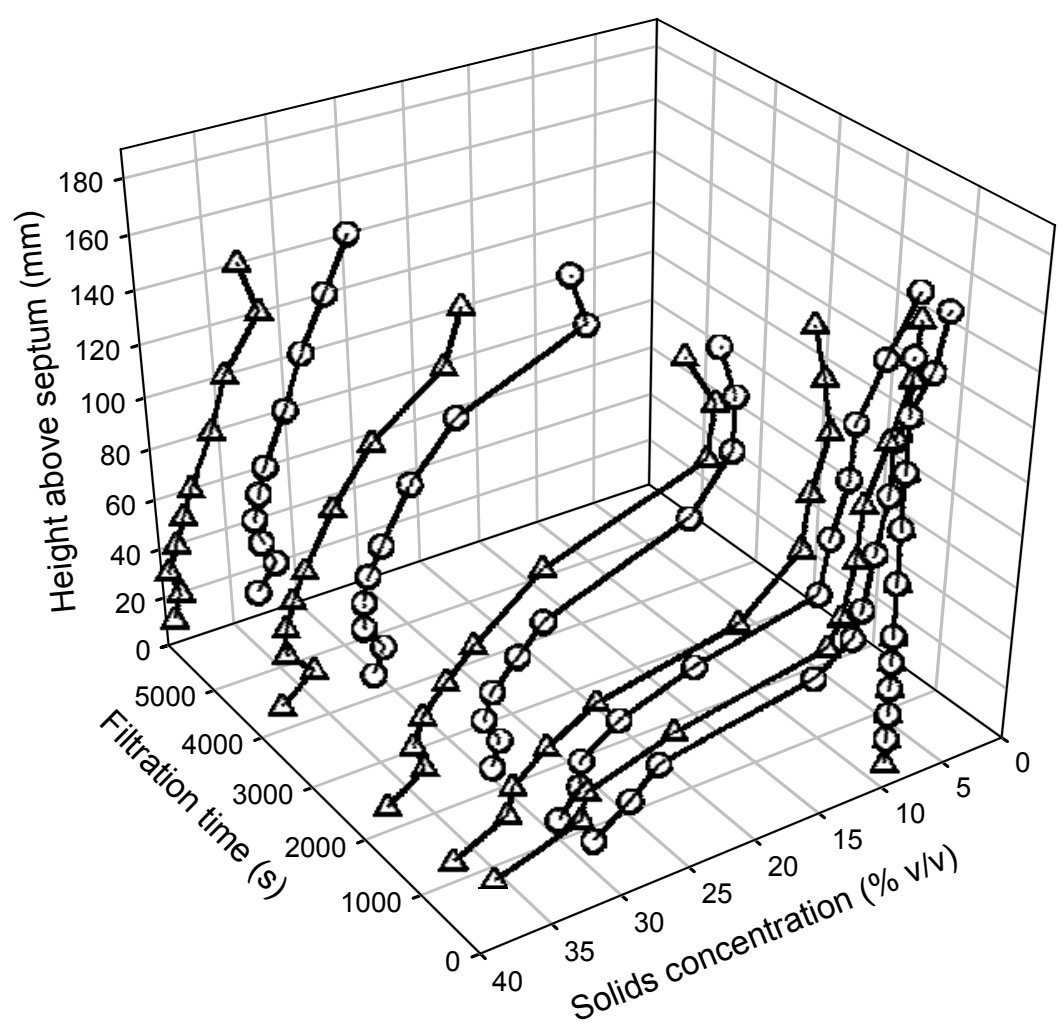

Figure 9: Progressive compressible cake formation during the constant pressure filtrations of talc suspensions. Filtration pressure $=100 \mathrm{kPa}$ (circles) and $600 \mathrm{kPa}$ (triangles); feed concentration $=$ $10 \% \mathrm{v} / \mathrm{v}$.

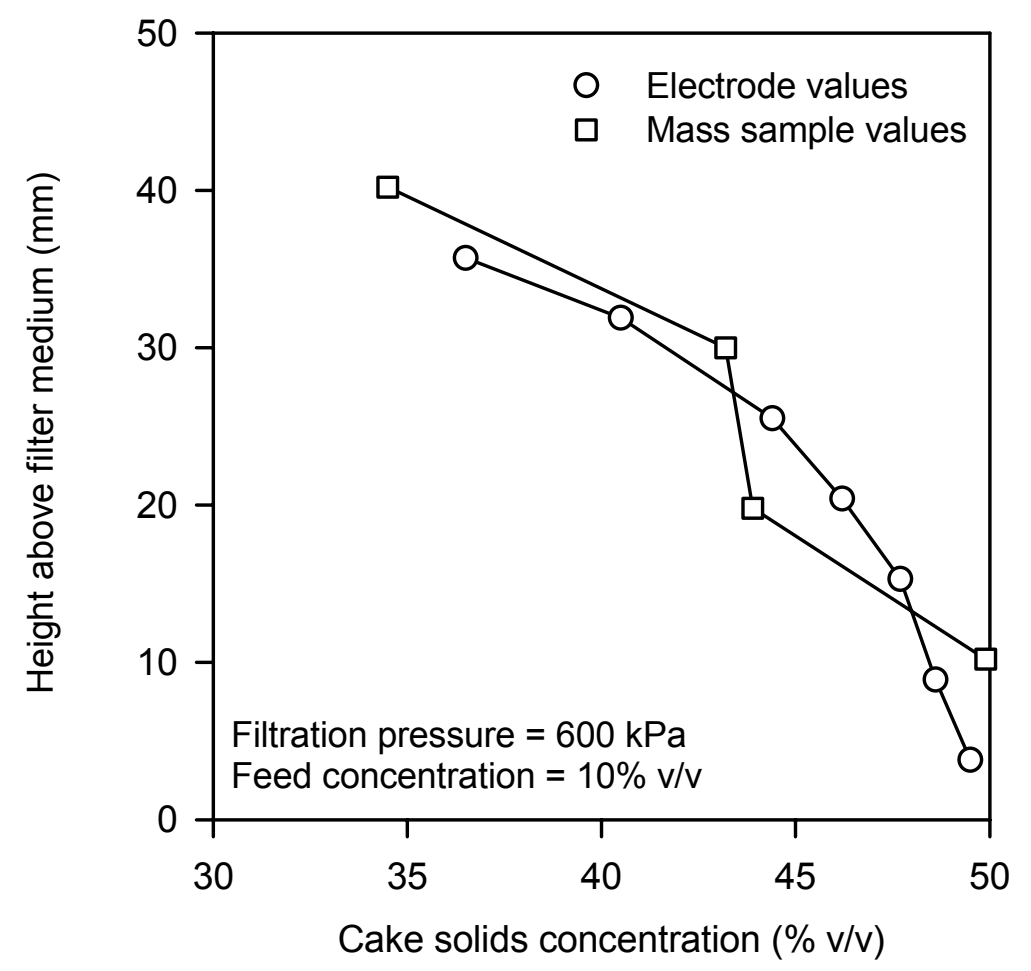

Figure 10: Comparison between mass sampling and electrode derived determinations of cake solids concentrations at the end of a zinc sulphide filtration. 


\begin{tabular}{|l|l|l|l|}
\hline & $\begin{array}{l}\text { Electrodes (electrical } \\
\text { resistance) }\end{array}$ & $\begin{array}{l}\text { Pressure } \\
\text { transducers }\end{array}$ & X-rays etc. \\
\hline Type of field & soft (i.e. electric field & n/a & $\begin{array}{l}\text { hard (i.e. passage } \\
\text { of radiation is not } \\
\text { distorted) }\end{array}$ \\
\hline (Potential) accuracy & moderate-good & $\begin{array}{l}\text { can be good } \\
\text { (depending on the } \\
\text { quality of transducer) }\end{array}$ & good \\
\hline fpeed of measurement & fast & fast & can be slow \\
\hline Ease of use & good & good & poor \\
\hline $\begin{array}{l}\text { Ability to measure a range } \\
\text { of cake properties }\end{array}$ & good & can be high & poor \\
\hline Cost & relatively low & & very high \\
\hline
\end{tabular}

Table 1: Summary of the methods for assessing cake structure in filtration processes.

\begin{tabular}{|l|l|l|l|}
\hline Measured parameter & Calcite & Talc & Zinc sulphide \\
\hline $50 \%$ particle size $(\mu \mathrm{m})$ & 11.3 & 8.5 & $3-15.6^{*}$ \\
Particle shape & Rhomboidal & Platelet & Oblate ellipsoid \\
Max. 5 -potential $(\mathrm{mV})$ & $-20(\mathrm{pH}=9)$ & $-55(\mathrm{pH}=11)$ & $-50(\mathrm{pH}=12)$ \\
Iso-electric $\mathrm{pH}$ & 9 & 2 & 2 \\
\hline
\end{tabular}

* could vary significantly dependent on the chosen $\mathrm{pH}$ and state of dispersion

Table 2: Some characterising properties of the feed suspensions made up from distilled water and mineral powder. 